\title{
A Comparison of the Bow-Tie and STAMP Approaches to Reduce the Risk of Surgical Instrument Retention
}

\author{
Maria Mikela Chatzimichailidou ${ }^{1,2,{ }^{*}}$, James Ward $^{1}$, Tim Horberry ${ }^{1,3}$, P. John Clarkson ${ }^{1}$ \\ ${ }^{1}$ Engineering Design Centre, Department of Engineering, University of Cambridge, UK \\ ${ }^{2}$ Centre for Transport Studies, Civil and Environmental Engineering, Imperial College \\ London, UK \\ ${ }^{3}$ Monash University Accident Research Centre, Melbourne, Australia
}

\begin{abstract}
Although relatively rare, surgical instrument retention inside a patient following Central Venous Catheterisation still presents a significant risk. The research presented here compared two approaches to help reduce retention risk: Bow-Tie Analysis and SystemsTheoretic Accident Model and Processes. Each method was undertaken separately and then the results of the two approaches were compared and combined. Both approaches produced beneficial results that added to existing domain knowledge, and a combination of the two methods was found to be beneficial. For example, the bow-tie analysis gave an overview of which activities keep controls working and who is responsible for each control, and the Systems-Theoretic Accident Model and Processes revealed the safety constraints that were not enforced by the supervisor of the controlled process. Such two-way feedback between both methods is potentially helpful for improving patient safety. Further methodology ideas to minimise surgical instrument retention risks are also described.
\end{abstract}

Keywords: Bow-tie, STAMP, STPA; CVC process; guidewire retention

\section{Introduction}

\subsection{Central Venous Catheterisation}

The focus of this research was on surgical instrument retention following Central Venous Catheterisation (CVC). CVC is a commonly-used medical procedure to gain access to a patient's venous system for a wide range of purposes such as delivering intravenous medication and taking measurements (Horberry, 2014). There are more than 200,000 CVC insertions annually in the UK and 6 million in the USA (Sivasubramaniam and Hiremath, 2008). However, an often overlooked potential complication is the inadvertent total loss intravascularly of part of the CVC set - a long, flexible, metal guidewire. Guidewire retention has been reported at a rate of 1 in 3,291 procedures in one medical establishment (Vannucci et al, 2013), although the actual incidence may be even higher due to underreporting (Auweiler et al, 2005; Horberry et al, 2014; Sloane, 2013; Ward et al, 2013; Ward et al, 2016). 
During the CVC procedure, a small needle first enters the target vein. A flexible metal guidewire is inserted through the needle and into the vein, and the needle is then removed. With the guidewire in position, a dilator is passed over it into the vein to increase the diameter of the opening, and then is withdrawn. The catheter - also known as a central line - is then threaded over the guidewire and into the vein until the outer (proximal) end of the guidewire projects from the catheter. The guidewire is removed and the catheter secured against the patient's skin before it is used (Horberry, 2014).

A retained guidewire in the patient's body may cause no overt symptoms for a prolonged period of time; however, in other cases, significant harm can occur, for example due to guidewire fracture (Guo et al, 2006; Kim et al, 2013; Pérez-Díez et al, 2007). Equally, if too many retained instrument events occur the risk of institutional reputation loss can be significant (Horberry et al, 2014; NHS England, 2015; Regenbogen et al, 2009; Sloane, 2013).

Guidewire retention is, theoretically, a completely preventable event provided that the operator grips the wire at all times and then removes it. Human factors issues previously attributed to guidewire loss include: inexperience with the technique, lack of supervision, tiredness, distractions, task interruptions and a general lack of awareness of the potential complications in central lines amongst the health professionals (Campbell et al, 2012; Horberry et al, 2014; Schummer et al, 2002; Teng et al, 2014; Vannucci et al, 2012). These human element issues can contribute to the chances of guidewires being retained but, as described later in this paper, they also can offer potential points of intervention to prevent wire loss.

\subsection{Aims of the research}

Given that CVC is such a widely-used medical procedure and the risks of guidewire retention following CVC are not as low as practicable, the aim of this research was to compare two approaches (Bow-Tie Analysis - BTA, and Systems-Theoretic Accident Model and Processes STAMP) with a view to helping to reduce retention risks. These two approaches were chosen because they undertake analysis at different levels: with BTA focusing on individual controls and STAMP focusing on systems-wide interventions. As such, it was anticipated that a combination of the two approaches might also offer benefits to understand and reduce guidewire retention risks.

Considering BTA in conjunction with STAMP, it was anticipated that the former can give an overview of what activities keep a control working and who is responsible for that control. In turn, STAMP can reveal the safety constraints that were not enforced by the controller and the appropriate control actions provided but not followed. Thus, it was anticipated that there may be two-way feedback between the two methods.

\subsection{A systems approach to healthcare}

In accident analysis research, it is now widely accepted that failures do not just occur at a human level but tend to be grounded in the wider system (Hollnagel, 2004; Salmon, 2012) and in the interaction of the many components within such systems. A failure to consider the wider system can result in unfair blame to individuals (Underwood and Waterson, 2013) 
and ineffective solutions to mitigate risk. These are both acute and long-standing problems in healthcare (Bagian, 2015). As a result, a number of Systemic Accident Analysis methods have emerged, including AcciMap (Rasmussen, 1997), STAMP (Leveson, 2004) and FRAM (Hollnagel, 2004). The research in this paper thus used a systems perspective to analyse the guidewire retention issue (Buckle et al, 2006; Clarkson et al, 2004; Horberry et al, 2014). Such an approach suggests that the goal is not to reduce human behaviour to rule-following, but to design a system in which individual responsibility and competence can effectively help create desired outcomes (Dekker and Leveson, 2014a).

As an example, a flawed hospital system, rather than flawed individuals, is responsible for patient harm (Dekker and Leveson, 2014a). In this example, a hospital is considered as a dynamic and complex system and its behaviour reflects the linkages and interactions among the components or entities that make up the entire system (Leveson et al, 2016). Hence, a critical question that the systems approach pursues is not why bad operators make mistakes, but why good ones do (Dekker and Leveson, 2014b). Ultimately, the dichotomy that it is either the people or the system that cause harmful events is misleading. Instead, the emphasis should be on people in systems: improving the system that identifies and deals with professional competence from pre-medical education onwards (Dekker and Leveson, 2014b).

In essence, the goal is to design systems in such a way to reduce human error (Leveson et al, 2016). To achieve this, in the engineering domain, the type of prospective analysis required is called hazard analysis (Leveson et al, 2016). For this reason, this study adapts a systemstheoretic prospective hazard analysis to a healthcare setting to identify scenarios leading to unwelcome situations so they can be designed (or redesigned) out of the system before losses occur (Leveson et al, 2016).

\subsection{Bow-Tie Analysis}

One of the approaches used to analyse the risk of guidewire retention following CVC was Bow-Tie Analysis (BTA). BTA is an increasingly popular approach often employed in highhazard industries such as mining and aviation (Burgess-Limerick et al, 2014; Pitblado and Weijand, 2014; Civil Aviation Authority, 2015). Recently, bow-ties have also been successfully used in medical safety (e.g., Kerckhoffs et al, 2013; Ward et al, 2016; Wierenga et al, 2009). Equally, BTA can show both existing controls and potential/recommended controls for hazards as well as highlighting where gaps in control may exist (Ward et al, 2016). One of the particular strengths of BTA is that it provides a quickly understood overview of the risk controls linked to initiating events (Kirsch et al, 2012).

BTA combines features of fault-tree and event-tree analysis to identify initiating events within an incident, their contributing factors and consequences, and both preventative and mitigating control measures (De Dianous and Fievez, 2006; Chevreau et al, 2006). As noted by de Ruijtera and Guldenmund (2016) and Pitblado and Weijand (2014), BTA currently lacks a fully consistent approach. However, at the heart of each bow-tie is an initiating event (that is, loss of control of the hazard leading to increased risk). In this research, the initiating 
event is the guidewire being retained inside a patient. To the left of the initiating event the contributing factors and preventative controls are shown; and on the right, the mitigating controls and consequences are displayed (Pitblado and Weijand, 2014).

\subsection{A Hazard Analysis Based on the STAMP Accident Model}

STAMP (Systems-Theoretic Accident Model and Processes) is a relatively new type of accident model, based on systems theory rather than the traditional analytic reduction and reliability theory (Leveson, 2004). It mainly advocates that accidents involve a complex, dynamic process, meaning that they are not simply chains of component failure events. For this reason, and falling under the scope of the STAMP model of accident causation, safety is an emergent property that arises when system components interact with each other within a larger environment.

In STAMP, systems are viewed as interrelated components kept in a state of dynamic equilibrium by feedback control loops. Figure 1 illustrates such a loop; the main elements of which are denoted in bold. There are four different types of element. The controller enforces safety constraints on other controllers, located at lower hierarchical levels, and ensures the safety of the system part he/she/it controls. The controller also issues commands to the actuator; the main responsibility (Leveson, 2011) of which is to execute control actions issued by the controller in order to bring the controlled process to equilibrium. The sensors take readings from the controlled process and feed the controller with data, and the controlled process is a task performed by the controller(s), either it is a human or an automated system. 


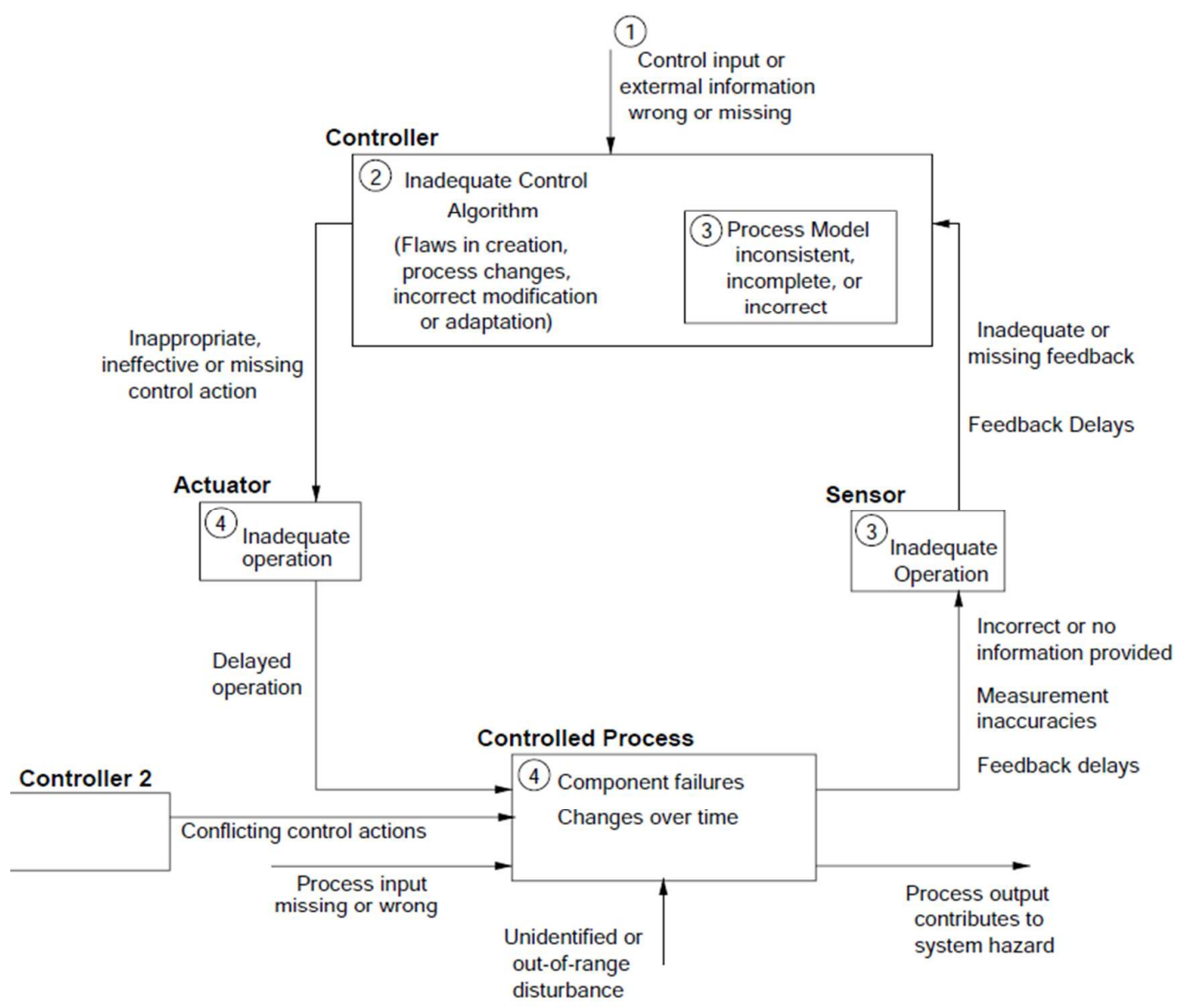

Figure 1: A standard control loop and the causal factors to be considered to create accident scenarios (adapted from Leveson, 2011)

STPA (Systems-Theoretic Process Analysis) is a hazard analysis technique that encapsulates the principles of the STAMP accident causality model. Because STPA is a top-down system engineering approach to system safety, it can be used early in the system development process to generate high-level safety requirements and constraints (Leveson, 2011). STPA is a method that identifies inadequate control actions and aims to examine scenarios or paths to accidents. STPA also includes those factors not included or poorly handled by the traditional hazard analysis methods, such as software requirements errors, component interaction accidents, complex human decision-making errors, inadequate coordination among multiple controllers, and flawed management and regulatory decision-making (Leveson, 2014). Within this model, safety is treated as a dynamic control problem, rather than a component reliability problem.

STPA has two main stages: (1) Identify the potential for inadequate control of the system that could lead to a hazardous state that results from inadequate control or enforcement of the safety constraints; and (2) Determine how each potentially hazardous control action identified in the previous stage could occur. 
The first stage requires consideration of: (a) a control action required for safety is not provided or not followed, (b) an unsafe control action is provided, (c) a potentially safe control action is provided too early or too late, that is, at the wrong time or in the wrong sequence, or (d) a control action required for safety is stopped too soon or applied too long. The second stage may be accomplished by: (a) for each unsafe control action, examining the parts of the control loop (see Figure 1) to check if they could cause it and (b) considering how the designed controls could degrade over time, and building in protection modules. It should be noted, however that for a complete STPA hazard analysis intermediate steps need to be taken.

\section{Methodology}

The BTA and STAMP methods were initially undertaken separately.

A BTA for guidewire retention inside a patient following CVC was described by Ward et al (2016). Full details of the method can be found in Ward et al (2016), but a summary follows. The paper describe how they created a list of the potential contributing factors to this event, and the potential consequences by reviewing the outputs from a range of methods previously used by the authors. These included interviews with CVC users and observations of catheterisations (Horberry et al, 2014). The measures which can reduce the probability of the guidewire being retained (preventive controls), and the measures which can be taken to detect the guidewire after it has been retained (mitigating controls) were then listed. Three members of the project team (with backgrounds in medicine, human factors and safety science) then created the bow-tie. Finally, this was reviewed by four medical staff who were familiar with the CVC process, and further iterations were made.

For STAMP, the analysis of the system started with several meetings with clinicians in order to gather data and extract useful conclusions about the actual system. Once this had taken place, there was sufficient data for the research team to complete the STPA hazard analysis.

\section{Results}

\subsection{Bow-tie results}

A guidewire being retained inside a patient was defined as the initiating event for the BTA. Figure 2 shows the potential contributing factors and consequences, and the preventive and mitigating controls. The BTA visually compares the current system against recommended changes: highlighted in grey italics are barriers that were known potential measures prior to the research, while those in black are possible measures that emerged through the research. 


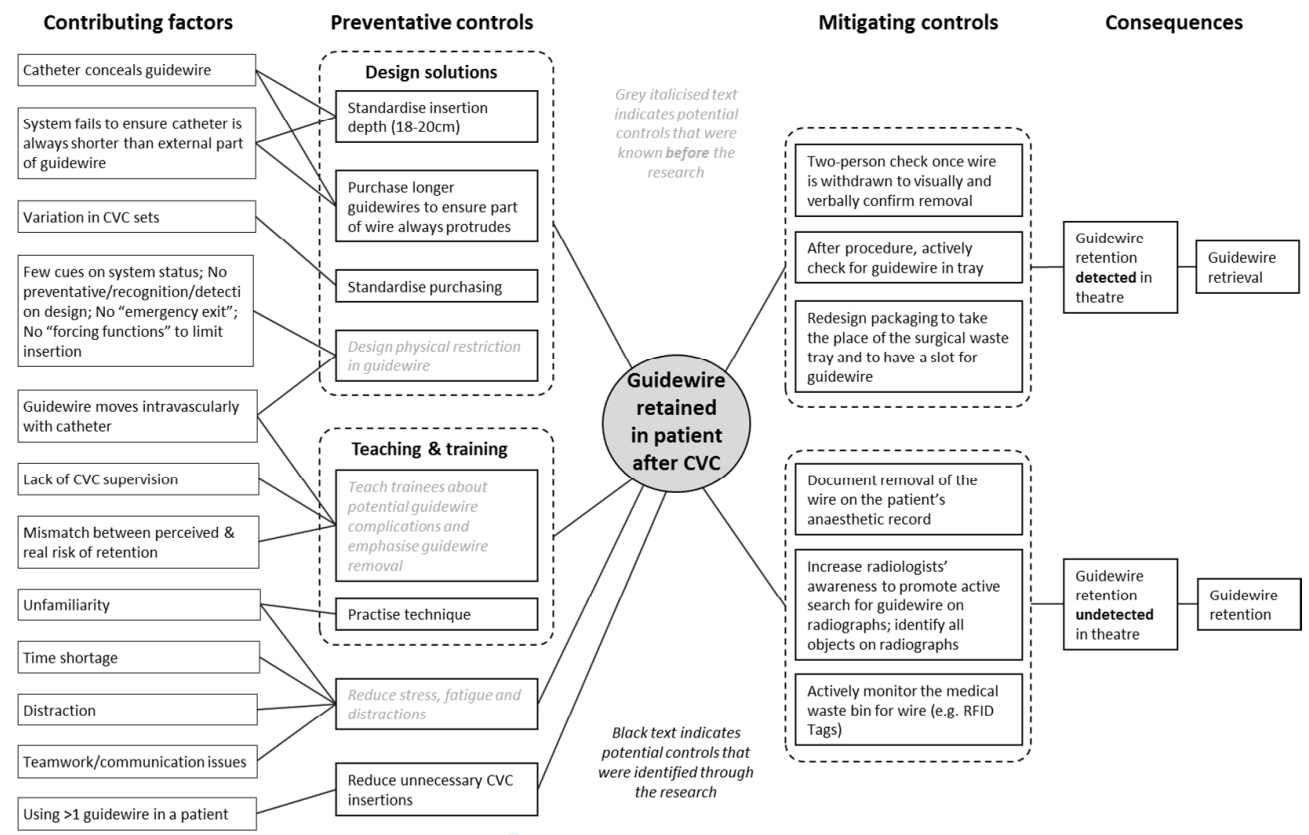

Figure 2: Guidewire retention BTA (from Ward et al, 2016)

\subsection{STPA Results}

As stated above, BTA in healthcare has been undertaken before, e.g. Ward et al (2016), but STAMP and STPA have been little used in this domain. In Section 1.5 the authors presented the two main stages of the STPA analysis, while in this section they elaborate more on its intermediate steps. Although the method is fully described from Step 1 to Step 9, the full results of the analysis are not presented.

According to the STPA, accident/losses (Step 1), hazard(s) (Step 2), and system level safety constraints (Step 3) should be defined. Thus, for the CVC process, these three steps gave the following results:

\begin{tabular}{|l|l|}
\hline Accident or loss & $\begin{array}{l}\text { Loss of human life or deterioration of health due to a retained guidewire, } \\
\text { which may fracture, cause thromboembolic complications, cause infection, or } \\
\text { lead to cardiac perforation and tamponade (Peh et al, 2016). }\end{array}$ \\
\hline $\begin{array}{l}\text { Hazard } \\
\text { (system level) }\end{array}$ & $\begin{array}{l}\text { Retained guidewire; loss of the guidewire during procedure, or unrecognised } \\
\text { failure to remove the guidewire (Amit et al, 2016). }\end{array}$ \\
\hline $\begin{array}{l}\text { System safety } \\
\text { constraint }\end{array}$ & $\begin{array}{l}\text { The anaesthetist shall remove the guidewire from the catheter and place it in } \\
\text { the tray. }\end{array}$ \\
\hline
\end{tabular}

Using the components of the control loop of Figure 1 as a guide, the control structure is created in Step 4. The safety control structure of the CVC process that STPA is performed for is the one in Figure 3. 

surgeon begins to operate, training doctor, external disturbance (e.g. phone calls, doors opening etc.)

Figure 3: Safety control structure of the CVC process.

As shown in Figure 3, the control structure includes the human controller, i.e., the anaesthetist, who is responsible for the CVC task. He/she executes and controls (i.e., plays the role of the actuator) the CVC process (i.e., the controlled process) based on his/her experience (i.e., their mental model), in combination with data from the Operating Department Practitioner (ODP - i.e. the anaesthetist's assistant) and his/her own senses (i.e., sensors).

Due to space saving reasons, only indicative examples related to possible guidewire retention (from Steps 5 through to Step 9 of the STPA process) are presented here. Given that the responsibility of the anaesthetist (Step 5) is to perform the CVC process, in Step 6 we defined (a) his/her control actions (CAs) and (b) the types of unsafe control actions (UCAs). Overall, the analysis led to 11 CAs and 21 UCAs in total. The final row of Table 1 includes the most relevant CAs and UCAs for guidewire retention. However, as a matter of sequence, the CAs and associated UCAs that preceded these are given in the first row of Table 1. Appendix I includes all the CAs and UCAs involved in a possible accident of retained guidewire. 
Table 1: Indicative results from STPA Step 6.

\begin{tabular}{|c|c|c|c|c|}
\hline \multirow[b]{2}{*}{$\begin{array}{l}\text { Control } \\
\text { Action }\end{array}$} & \multicolumn{4}{|c|}{ Types of Unsafe Control Actions [UCA] } \\
\hline & $\begin{array}{l}\text { 1. Not Providing } \\
\text { Causes Hazard }\end{array}$ & $\begin{array}{l}\text { 2. Providing } \\
\text { Causes Hazard }\end{array}$ & $\begin{array}{c}\text { 3. Too Early/ Too } \\
\text { Late/ Wrong Causes } \\
\text { Hazard }\end{array}$ & $\begin{array}{c}\text { 4. Stopping Too } \\
\text { Soon/ Applying it } \\
\text { Too Long Causes } \\
\text { Hazard }\end{array}$ \\
\hline $\begin{array}{l}\text { [CA8] Insert } \\
\text { the catheter } \\
\text { over the } \\
\text { guidewire }\end{array}$ & Not hazardous & $\begin{array}{l}\text { [UCA13] Insert } \\
\text { the catheter } \\
\text { over the } \\
\text { guidewire } \\
\text { provided when } \\
\text { guidewire does } \\
\text { not remain in } \\
\text { place, i.e. it } \\
\text { moves deeper } \\
\text { inside the vein }\end{array}$ & $\begin{array}{l}\text { [UCA14] Insert the } \\
\text { catheter over the } \\
\text { guidewire provided } \\
\text { wrongly, before the } \\
\text { anaesthetist pinches } \\
\text { the external tip of the } \\
\text { guidewire }\end{array}$ & $\begin{array}{l}\text { [UCA15] Insert the } \\
\text { catheter over the } \\
\text { guidewire stopped } \\
\text { too soon when the } \\
\text { external tip of the } \\
\text { guidewire is not } \\
\text { reachable }\end{array}$ \\
\hline $\begin{array}{l}\text { [CA9] } \\
\text { Remove the } \\
\text { guidewire }\end{array}$ & $\begin{array}{l}\text { [UCA16] Remove } \\
\text { the guidewire not } \\
\text { provided when } \\
\text { catheter } \\
\text { placement is } \\
\text { completed }\end{array}$ & Not hazardous & $\begin{array}{l}\text { [UCA17] Remove the } \\
\text { guidewire provided } \\
\text { too late, i.e. } \\
\text { postoperative, when } \\
\text { the patient has } \\
\text { already undergone } \\
\text { the surgery }\end{array}$ & Not hazardous \\
\hline
\end{tabular}

In STPA Step 7, we restated all UCAs as safety constraints. A useful way to do this is to add or remove a negation. [UCA16], for instance, can be translated into a safety requirement as follows: "The anaesthetist shall remove the guidewire when CVC process is completed".

Next, in Step 8, for every element of the control structure (Figure 3), we considered possible flaws that may contribute to the occurrence of [UCA16] and [UCA17] identified in Table 1. To define these flaws, the STPA hazard analysis offers guidance through the fixed guidewords given in Figure 1. Figure 1 was also used as a template to generate Figure 4 and the bullet points correspond to the guidewords of Figure 1. This step led to the causal factors (CF) of Figure 4. 
In the final step, Step 9, flaws were translated into safety requirements. In a similar manner as previously, if a flaw (see Figure 4) is composed in the following way: "Central line pack design changes not reported beforehand", the corresponding safety requirement, i.e. [SR3], could be expressed as shown in Table 2, row 3. Results in Table 2 refer to all the flaws identified by STPA for [UCA6] and [UCA7], and are translated into safety requirements. Table 2 also compares the STPA results to those obtained for the Bow-tie Analysis. Each safety requirement was compared to the data obtained in the BTA, and whether they were: (a) identified by the BTA - "YES", (b) not identified- "NO" or (c) implied - "MAYBE".

Table 2: Results from STPA Step 9.

\begin{tabular}{|c|c|c|c|c|}
\hline \multirow[b]{2}{*}{ STPA results } & \multirow{2}{*}{$\begin{array}{l}\text { Figure } 4 \\
\text { May } \\
\text { relate to }\end{array}$} & \multicolumn{3}{|c|}{ Bow-tie } \\
\hline & & YES & NO & MAYBE \\
\hline $\begin{array}{l}\text { [SR1] Anaesthetist shall receive simulation training under } \\
\text { realistic and critical conditions before performing CVC }\end{array}$ & CF1 & $\mathbf{x}$ & & \\
\hline $\begin{array}{l}\text { [SR2] Anaesthetist shall be informed of changes about design } \\
\text { changes in medical devices }\end{array}$ & CF2; CF3 & $\mathbf{x}$ & & \\
\hline $\begin{array}{l}\text { [SR3] Hospital management shall ensure that anaesthetists } \\
\text { work in an environment where distractions/interruptions are } \\
\text { minimised }\end{array}$ & $\begin{array}{l}\text { CF8; CF9; } \\
\text { CF10 }\end{array}$ & $x$ & & \\
\hline $\begin{array}{l}\text { [SR4] Anaesthetist shall consult another anaesthetist in case } \\
\text { of not feeling well/confident }\end{array}$ & $\begin{array}{l}\text { CF11; } \\
\text { CF13; } \\
\text { CF14; } \\
\text { CF15 }\end{array}$ & & $x$ & \\
\hline $\begin{array}{l}\text { [SR5] Hospital management shall plan health checks for } \\
\text { medics or build health checks into the annual medical } \\
\text { revalidation procedure }\end{array}$ & CF13 & & $\mathbf{x}$ & \\
\hline $\begin{array}{l}\text { [SR6] Hospital management shall encourage self-reporting of } \\
\text { near-misses by anaesthetists }\end{array}$ & $\begin{array}{l}\text { CF11; } \\
\text { CF13; } \\
\text { CF14; } \\
\text { CF15 }\end{array}$ & & $\mathbf{x}$ & \\
\hline $\begin{array}{l}\text { [SR7] Anaesthetist shall perform CAs with continuity and with } \\
\text { the maximum possible concentration }\end{array}$ & $\begin{array}{l}\text { CF3; CF4; } \\
\quad \text { CF5 }\end{array}$ & & & $\mathbf{x}$ \\
\hline
\end{tabular}




\begin{tabular}{|c|c|c|c|c|}
\hline $\begin{array}{l}\text { [SR8] Surgeon shall undertake his/her tasks only when } \\
\text { anaesthetist stands off the patient }\end{array}$ & CF6; CF8 & & $x$ & \\
\hline $\begin{array}{l}\text { [SR9] A must-not-do list shall be given to trainee } \\
\text { anaesthetists }\end{array}$ & CF9 & & $\mathbf{x}$ & \\
\hline $\begin{array}{l}\text { [SR10] Potential complications of CVC shall be made clear to } \\
\text { trainee doctors and medics in general, especially regarding } \\
\text { retained guidewires }\end{array}$ & $\begin{array}{c}\text { CF1; CF7- } \\
\text { 9; CF11; } \\
\text { CF12; } \\
\text { CF14; } \\
\text { CF15 }\end{array}$ & & $\mathbf{x}$ & \\
\hline $\begin{array}{l}\text { [SR11] Sign on the door stating that anaesthetic is in progress } \\
\text { shall be placed, or a traffic light system to the door shall be } \\
\text { added, to warn those who want to enter the anaesthetic } \\
\text { room / operating (not operation) theatre }\end{array}$ & CF8; CF12 & & & $\mathbf{x}$ \\
\hline $\begin{array}{l}\text { [SR12] ODP/nurse/ anaesthetist shall brief incoming surgeon } \\
\text { about the development of the process prior to the beginning } \\
\text { of the surgical procedure }\end{array}$ & $\begin{array}{l}\text { CF10; } \\
\text { CF12 }\end{array}$ & & $\mathbf{x}$ & \\
\hline $\begin{array}{l}\text { [SR13] Completion of CVC steps, including guidewire } \\
\text { removal, shall be confirmed and acknowledged }\end{array}$ & CF11-C15 & & $x$ & \\
\hline $\begin{array}{l}\text { [SR14] ODP shall concentrate on the process; otherwise ask } \\
\text { for replacement }\end{array}$ & CF12 & $\mathbf{x}$ & & \\
\hline $\begin{array}{l}\text { [SR15] ODP shall interrupt anaesthetist if guidewire removal } \\
\text { omitted }\end{array}$ & $\begin{array}{l}\text { CF12; } \\
\text { CF13- } \\
\text { CF15 }\end{array}$ & & $x$ & \\
\hline [SR16] Removal of guidewire shall be announced audibly & $\begin{array}{l}\text { CF12; } \\
\text { CF14; } \\
\text { CF15 }\end{array}$ & & & \\
\hline $\begin{array}{l}\text { [SR17] ODP and anaesthetist shall check if guidewire in tray } \\
\text { before leaving the operation theatre }\end{array}$ & $\begin{array}{l}\text { CF12; } \\
\text { CF14; } \\
\text { CF15 }\end{array}$ & $x$ & & \\
\hline
\end{tabular}

\section{Discussion: Comparison of the BTA and STPA Approaches}

It is important to note that a full one-by-one comparison of the results of the two analyses is not possible, due to the different nature and complexity of STPA and BTA. For example, examining the bow-tie diagram in Figure 2 allows for a match with the STPA safety requirements related to preventative and mitigating controls. In this way, the STPA safety requirements for guidewire retention can be categorised into preventative and mitigating requirements. Conversely, in Table 2, there are safety requirements not identified by the BTA; such as the ODP being encouraged to interrupt the anaesthetist if guidewire has not been removed.

The research found that BTA provides an effective way of displaying and examining the contributing factors, consequences, and potential preventative and mitigating control measures or barriers associated with a guidewire-retention incident. So the main function of BTA can perhaps be viewed as an effective risk communication tool to link together guidewire retention events with their contributing factors, controls and consequences and to highlight both existing and missing/possible barriers. As such, it could be seen as a 
prospective rather than merely reactive medical safety management tool (Kerckhoffs et al, 2013).

Similarly, the STPA results indicate that events leading to guidewire retention occur because safety constraints were not successfully implemented. That is, STPA, like BTA, is a prospective analysis tool that shifts the emphasis in system safety from preventing failures to making behavioural changes (Leveson, 2011), e.g. implementing safety requirements after a systemic analysis and considering the interactions between the system elements.

Considering BTA in conjunction with STPA, the former gives an overview of what activities keep a control working. In turn, STPA reveals who is responsible for controls and the safety constraints that were not enforced by the controller, i.e. in this case the anaesthetist, and the appropriate control actions that are provided but are not followed. In other words, BTA gives the 'big picture', whilst STAMP guides the identification of scenarios that lead to hazardous control actions and violate the system component safety constraints. Given this notion, STPA could feed into the bow-tie to identify other contributing factors and controls for a revised bow-tie diagram. Such an approach could make a positive impact on improving the risk management systems of an organisation. For example, they could be used in dynamic risk assessment by means of updating the bow-tie (with STPA input) regularly in response to changing circumstances such as new equipment or procedures being introduced.

Of course, care should be taken in extrapolating from the single topic explored in this paper to healthcare as a whole in terms of reliability and validity of the methods employed (Stanton et al, 2013). However, it is argued here that the combination of approaches presented in this paper might help push analysis of healthcare incidents and barriers a little further. In this direction, further work in combining the BTA and STPA approaches for other 'never-events' in healthcare (e.g. wrong site surgery) is being considered, and the current work examining retained surgical instruments is receiving further input and validation from experienced anaesthetists.

Other potential limitations include the guide words or "generic factors" (Leveson 2011) which are used in STPA to help locate safety hazards. These may restrict the analysis. For instance, they may limit the scope of the investigation and the potential of the analyst to significantly contribute to the richness of the study. Conversely, however, the guide words facilitate the identification of risk reduction measures, rather than simply adding redundancy or overdesigning in order to deal with component failures. For STPA, building the safety control structure, like the one in Figure 3, may be challenging for non-specialists, and requires a high level of system knowledge - an issue which has also been highlighted by Salmon et al, (2012).

Pitblado and Weijand have also highlighted the risk that the quality of a BTA can be degraded by a lack of knowledge of how to apply it properly. If this occurs in industries that are already familiar with similar methods, this may be an even greater barrier to success in the context of healthcare. Healthcare is a sector which tends to use proactive assessment methods sparingly, relying more on retrospective accident analysis methods such as Root 
Cause Analysis (RCA). It could be argued that RCA is a simpler method than BTA and STAMP, and yet the quality of many RCAs is still questionable (Trbovich \& Shojania, 2017; Wu et al, 2008), not least due to a lack of time to perform a comprehensive analysis (Braithwaite et al, 2006). Thus, both types of analysis would require an experienced and multidisciplinary team, supported by adequate resources.

In terms of reducing the risk of retained surgical instruments, the BTA identified a number of possible solutions. These include suggestions for reducing distractions, design solutions including using longer wires and designing a device which physically restricts the movement of the wire, and educating trainee anaesthetists about the risks of guidewire retention during CVC. Although potentially helpful, many of these ideas have been suggested in other publications (Horberry et al, 2014; Lum et al, 2005; Omar et al, 2010; Williams et al, 2014; Teng et al, 2014).

The STPA analysis led to a range of possible solutions, many of which focus on wider issues such as modifying the working environment or the behaviour of clinicians, or adding administrative measures. Examples of these include installing access controls to the theatre, ensuring working space between the surgeon and the anaesthetist and alerting anaesthetists to any design changes. In general, these solutions are more novel than those suggested elsewhere, but may suffer from a range of challenges in terms of practical implementation. Furthermore, efforts to modify human behaviour may be well intended, but may also not be very effective (NIOSH, 2016) since they tend to address the symptom rather than the cause (Bagian, 2012). As such, validation of STPA analysis by Subject Matter Experts such as experienced anaesthetists is an important step before moving to practical implementation of the solutions generated.

\section{Conclusions}

The main conclusion of this paper is that BTA and STPA can complement each other. It is useful, for example, to have the bow-tie diagram in place, before starting to apply STPA, because it can give the analyst an insight of what to expect, and look for, in the later stages of the STPA analysis. This is mainly useful in cases where the analyst is not experienced enough to apply STPA. Due to its pictorial form, BTA offers an overview of the points where the analyst should pay more attention. This could help to focus the STPA, which is quite a lengthy process, and might save a substantial amount of analysis time as a result. Bow-tie diagrams could therefore have a supportive role towards STPA: this may result in a more robust analysis methodology through the integration of the two techniques and subsequent validation by Subject Matter Experts such as experienced anaesthetists.

Both the BTA and STPA methods produced a set of solutions to the guidewire retention issue, each solution varying in its novelty, ease of implementation and effectiveness. It is likely that utilising multiple solutions, preferably in an integrated approach that also involves end-user input, will be most effective in reducing the risk of retained guidewires. 


\section{Acknowledgements}

This research was funded by the National Institute for Health Research (NIHR) Collaboration for Leadership in Applied Health Research and Care East of England (CLAHRC EoE) at Cambridge and Peterborough NHS Foundation Trust. The views expressed are those of the author(s) and not necessarily those of the NHS, the NIHR or the Department of Health.

\section{References}

Amit, A., Jyotsna, S. and Kasyap, V.K. (2016). Retention of Guidewire: A Rare but Avoidable Complication of Central Venous Catheterization. Journal of Comprehensive Pediatrics, $7(1)$.

Auweiler M, Kampe S, Zähringer M, Buzello S, von Spiegel T, Buzello W, et al. (2005) The human error: delayed diagnosis of intravascular loss of guidewires for central venous catheterization. J Clin Anesth. Nov; 17(7):562-4.

Bagian, J. P. (2015). The Future of Graduate Medical Education. Academic Medicine, 90(9), 1199-1202.

Bagian, J. (2012). Health Care and Patient Safety: The Failure of Traditional Approaches How Human Factors and Ergonomics Can and MUST Help. Human Factors and Ergonomics in Manufacturing \& Service Industries. 22 (1) 1-6.

Braithwaite, J., Westbrook, M. T., Mallock, N. A., Travaglia, J. F., \& ledema, R. A. (2006). Experiences of health professionals who conducted root cause analyses after undergoing a safety improvement programme. Quality \& Safety in Health Care, 15(6), 393-9.

Buckle, P., Clarkson, P.J., Coleman, R., Ward, J. and Anderson. J. (2006). Patient Safety, Systems Design and Ergonomics. Applied Ergonomics, Special Issue: Meeting Diversity in Ergonomics, 37 (4).

Burgess-Limerick, R., Horberry, T., Steiner, L. (2014). Bow-tie analysis of a fatal underground coal mine collision. Ergonomics Australia, 2014 10:2.

Campbell, G., Arfanis, K., Smith A. F. (2012). Distraction and interruption in anaesthetic practice. British Journal of Anaesthesia. 109(5):707-15.

Chevreau, F.R., Wybo, J.L., \& Cauchois, D. (2006). Organizing learning processes on risks by using the bow-tie representation. Journal of Hazardous Materials, 130(3), 276-283.

Civil Aviation Authority (2015). Bowtie Document Library. Downloaded $16^{\text {th }}$ May 2017 from: https://www.caa.co.uk/Safety-initiatives-and-resources/Working-withindustry/Bowtie/Bowtie-templates/Bowtie-document-library/

Clarkson, P. J., Buckle, P. Coleman, R., Stubbs, D., Ward, J., Jarrett, J., Lane, R., \& Bound, J. (2004). Design for Patient Safety: A Review of the Effectiveness of Design in the UK Health Service. Journal of Engineering Design. 15 (2): 123-40. 
De Dianous, V. \& Fiévez, C. (2006). ARAMIS project: A more explicit demonstration of risk control through the use of bow-tie diagrams and the evaluation of safety barrier performance. Journal of Hazardous Materials, 130(3), 220-233.

De Ruijtera, A. \& Guldenmund, F. (2016). The bowtie method: A review. Safety Science, 6, $88,211-218$.

Dekker, S. W., \& Leveson, N. G. (2014a). The systems approach to medicine: controversy and misconceptions. BMJ quality \& safety, bmjqs-2014.

Dekker, S. W., \& Leveson, N. G. (2014b). The bad apple theory won't work: response to 'Challenging the systems approach: why adverse event rates are not improving' by $\mathrm{Dr}$ Levitt. BMJ quality \& safety, bmjqs-2014.

Guo H, Lee J-D \& Guo M. (2006). Guidewire loss: Mishap or blunder? Heart. 92(5):602.

Hollnagel, E. (2004). Barriers and accident prevention. Aldershot: Ashgate Publishing Ltd.

Horberry, T., Teng, Y.C., Ward, J., Patil, V., \& Clarkson, P.J. (2014). Guidewire retention following central venous catheterisation: a human factors and safe design investigation. The International Journal of Risk \& Safety in Medicine, 26(1), 23-37.

Kerckhoffs, M.C., van der Sluijs, A.F., Binnekade, J.M., \& Dongelmans, D.A. (2013). Improving patient safety in the ICU by prospective identification of missing safety barriers using the bow-tie prospective risk analysis model. Journal of Patient Safety, 9(3), 154-159.

Kim TJ, Kim JK, Park BM, Song PS, Kim DK, Kim KH, Seol SH, Kim DI. (2013). Fatal subacute stent thrombosis induced by guidewire fracture with retained filaments in the coronary artery. Korean Circ J. Nov;43(11):761-5.

Kirsch, P., Goater, S., Harris, J., Sprott, D., \& Joy, J. (2012). RISKGATE: Promoting and redefining best practice for risk management in the Australian coal industry. Proceedings of the 12th Coal Operators' Conference (pp. 315-325).

Leveson, N. (2004). "A new accident model for engineering safer systems." Safety Science. 42(4): 237-270.

Leveson, N. (2011). Engineering a safer world: Systems thinking applied to safety. Cambridge, Massachusetts: MIT Press.

Leveson, N., Samost, A., Dekker, S., Finkelstein, S., \& Raman, J. (2016). A Systems Approach to Analyzing and Preventing Hospital Adverse Events. Journal of patient safety.

Lum, Timothy E., Rollin J. Fairbanks, Elliot C. Pennington, and F L. Zwemer. (2005). "Profiles in Patient Safety: Misplaced Femoral Line Guidewire and Multiple Failures to Detect the Foreign Body on Chest Radiography." Academic Emergency Medicine: Official Journal of the Society for Academic Emergency Medicine. 12 (7): 658-62.

NHS England (2015). Serious Incident Framework. UK: NHS England. 
NIOSH (National Institute for Occupational Safety and Health) (2016). Hierarchy of Controls. Retrieved $21^{\text {st }}$ November 2016 from http://www.cdc.gov/niosh/topics/hierarchy/

Omar, Hesham R, Ahmed Fathy, Devanand Mangar, and Enrico Camporesi. (2010). "Missing the Guidewire: An Avoidable Complication." International Archives of Medicine. 3 (September): 21.

Peh, W.M., Loh, W.J. and Loo, C.M. (2016). Eliminating guidewire retention during ultrasound guided central venous catheter insertion via an educational program, a modified CVC set, and a drape with reminder stickers. BMJ Quality Improvement Reports, 5(1), pp.u209550-w3941.

Pérez-Díez D., Salgado-Fernandez J, Vazquez-Gonzalez N, Calvino-Santos R, VazquezRodriguez JM, Aldama-Lopez G, et al. (2007). Percutaneous retrieval of a lost guidewire that caused cardiac tamponade. Circulation. 115(24):629-31.

Pitblado, R., \& Weijand, P. (2014). Barrier diagram (Bow Tie) quality issues for operating managers. Process Safety Progress, 33(4), 355-361.

Rasmussen, J. (1997). Risk management in a dynamic society: a modelling problem. Safety Science, 27(2-3), 183-213.

Regenbogen, S. E., Greenberg, C. C., Resch, S. C., Kollengode, A., Cima, R. R., Zinner, M. J., \& Gawande, A. A. (2009). Prevention of retained surgical sponges: A decision-analytic model predicting relative cost-effectiveness. Surgery, 145, 527-535.

Salmon, P. M., Cornelissen, M., \& Trotter, M. J. (2012). Systems-based accident analysis methods: A comparison of Accimap, HFACS, and STAMP. Safety Science, 50(4), 11581170 .

Schummer W., Schummer C., Gaser E., Bartunek R. (2002) Loss of the guide wire: Mishap or blunder? British Journal of Anaesthesia; 88:144-6.

Sivasubramaniam, S., \& Hiremath, M. (2008). Central venous catheters: Do we need to review practice on positioning? Journal of the Intensive Care Society, 9(3), 228-231.

Sloane, T. (2013). The High Cost of Inaction: Retained Surgical Sponges are Draining Hospital Finances and Harming Reputations. Retrieved May 31, 2017, from http://www.beckershospitalreview.com/quality/the-high-cost-of-inaction-retainedsurgical-sponges-are-draining-hospital-finances-and-harming-reputations.html

Stanton, N., Salmon, P., Rafferty, L.A, Walker, G., Baber, C and Jenkins, D. (2013) Human Factors Methods: A Practical Guide for Engineering and Design. Second edition. UK: Ashgate Press.

Teng, Y.C., Ward, J. Horberry, T., Patil, V. and Clarkson, P.J. (2014). Retained Guidewires in Central Venous Catheterisation: An Analysis of Omission Errors. In S. Sharples and S. Shorrock (Eds.), Contemporary Ergonomics and Human Factors 2014 (pp211-214). UK: Taylor and Francis. 
Trbovich, P., \& Shojania, K. G. (2017). Root-cause analysis: swatting at mosquitoes versus draining the swamp. BMJ Quality \& Safety, 26(5), 350-353.

Underwood, P., \& Waterson, P. (2013). Systemic accident analysis: Examining the gap between research and practice. Accident Analysis \& Prevention, 55, 154-164.

Vannucci, A., Jeffcoat, A., Ifune, C., Salinas, C., Duncan, J.R., \& Wall, M. (2013). Retained guidewires after intraoperative placement of central venous catheters. Anesthesia \& Analgesia, 117(1), 102-108.

Ward, J., Teng, Y.C., Horberry, T., and Clarkson, P.J. (2013). Healthcare human reliability analysis - by HEART. In M. Anderson (Ed.), 'Contemporary Ergonomics and Human Factors 2013' (pp287-288). UK: Taylor and Francis.

Ward, J., Chatzimichailidou, M., Horberry, T., Teng, Y. and Clarkson, J. (2016). Guidewire Retention after Central Venous Catheterisation: Prevention and Mitigation using Bow-Tie Analysis. Book Chapter in 'Contemporary Ergonomics and Human Factors 2016' (pp9599). Edited by P. Waterson, R. Sims and E.M. Hubbard, Chartered Institute of Ergonomics and Human Factors: UK.

Wierenga, P.C., Lie-A-Huen, L., de Rooij, S.E., Klazinga, N.S., Guchelaar, H.J., \& Smorenburg, S.M. (2009). Application of the bow-Tie Model in medication safety risk analysis. Drug safety, 32(8), 663-673.

Williams, Tamara L., T. Andrew Bowdle, Bradford D. Winters, Stephen D. Pavkovic, and Marilyn K. Szekendi. (2014). "Guidewires Unintentionally Retained During Central Venous Catheterization." The Journal of the Association for Vascular Access. 19 (1): 29-34.

Wu, A. W., Lipshutz, A. K. M., \& Pronovost, P. J. (2008). Effectiveness and efficiency of root cause analysis in medicine. JAMA: The Journal of the American Medical Association, 299(6), 685-687. 
Appendix I

\begin{tabular}{|c|c|c|c|c|}
\hline \multirow{2}{*}{$\begin{array}{c}\text { Control Action [CA] / } \\
\text { Controller [C] }\end{array}$} & \multicolumn{4}{|c|}{ Types of Unsafe Control Actions [UCA] } \\
\hline & $\begin{array}{c}\text { 1. Not Providing Causes } \\
\text { Hazard }\end{array}$ & $\begin{array}{l}\text { 2. Providing Causes } \\
\text { Hazard }\end{array}$ & $\begin{array}{l}\text { 3. Too Early/ Too Late/ Wrong } \\
\text { Causes Hazard }\end{array}$ & $\begin{array}{l}\text { 4. Stopping Too Soon/ Applying } \\
\text { it Too Long Causes Hazard }\end{array}$ \\
\hline \multicolumn{5}{|l|}{ [C1] Anaesthetist } \\
\hline $\begin{array}{l}\text { [CA1] Insert the } \\
\text { needle to gain access } \\
\text { to the target vein }\end{array}$ & Not hazardous & $\begin{array}{l}\text { N/A for the specific } \\
\text { hazard }\end{array}$ & N/A for the specific hazard & N/A for the specific hazard \\
\hline $\begin{array}{l}\text { [CA2] Insert the } \\
\text { guidewire }\end{array}$ & Not hazardous & $\begin{array}{l}\text { N/A for the specific } \\
\text { hazard }\end{array}$ & N/A for the specific hazard & $\begin{array}{l}\text { [UCA1] Insert the guidewire } \\
\text { provided too long, situated too } \\
\text { deeply in the vein }\end{array}$ \\
\hline $\begin{array}{l}\text { [CA3] Remove the } \\
\text { needle }\end{array}$ & N/A for the specific hazard & Not hazardous & N/A for the specific hazard & N/A for the specific hazard \\
\hline $\begin{array}{l}\text { [CA4] Make a nick in } \\
\text { the skin }\end{array}$ & Not hazardous & $\begin{array}{l}\text { N/A for the specific } \\
\text { hazard }\end{array}$ & N/A for the specific hazard & N/A for the specific hazard \\
\hline \multirow{2}{*}{$\begin{array}{l}\text { [CA5] Insert the } \\
\text { dilator over the } \\
\text { guidewire }\end{array}$} & \multirow{2}{*}{$\begin{array}{l}\text { [UCA2] Insert the dilator over } \\
\text { the guidewire not provided } \\
\text { when the nick is not too wide }\end{array}$} & \multirow{2}{*}{$\begin{array}{l}\text { [UCA3] Insert the dilator } \\
\text { over the guidewire } \\
\text { provided when dilator } \\
\text { and guidewire move in at } \\
\text { the same time }\end{array}$} & \multirow{2}{*}{$\begin{array}{l}\text { [UCA4] Insert the dilator over the } \\
\text { guidewire provided wrongly, before } \\
\text { the anaesthetist pinches the } \\
\text { external tip of the guidewire }\end{array}$} & $\begin{array}{l}\text { [UCA5] Insert the dilator over } \\
\text { the guidewire stopped too soon } \\
\text { when the external tip of the } \\
\text { guidewire is not reachable }\end{array}$ \\
\hline & & & & $\begin{array}{l}\text { [UCA6] Insert the dilator over } \\
\text { the guidewire provided too long } \\
\text { when the guidewire is not visible } \\
\text { externally }\end{array}$ \\
\hline [CA6] Push the & [UCA7] Push the dilator into & [UCA8] Push dilator into & [UCA9] Push dilator into skin and & [UCA10] Push the dilator into \\
\hline
\end{tabular}




\begin{tabular}{|c|c|c|c|c|}
\hline $\begin{array}{l}\text { dilator into the skin } \\
\text { and the vein }\end{array}$ & $\begin{array}{l}\text { the skin and the vein not } \\
\text { provided when the guidewire } \\
\text { is not visible externally }\end{array}$ & $\begin{array}{l}\text { skin and vein provided } \\
\text { when it moves in at same } \\
\text { time with the guidewire }\end{array}$ & $\begin{array}{l}\text { the vein provided wrongly, before } \\
\text { the anaesthetist makes sure that } \\
\text { the guidewire is visible externally }\end{array}$ & $\begin{array}{l}\text { the skin and the vein provided } \\
\text { too long when the guidewire is } \\
\text { not visible externally }\end{array}$ \\
\hline $\begin{array}{l}\text { [CA7] Remove the } \\
\text { dilator }\end{array}$ & Not hazardous & $\begin{array}{l}\text { [UCA11] Remove the } \\
\text { dilator provided when the } \\
\text { anaesthetist does not } \\
\text { pinch the external tip of } \\
\text { the guidewire }\end{array}$ & $\begin{array}{l}\text { [UCA12] Remove the dilator } \\
\text { provided too early before the } \\
\text { anaesthetist pinches the external } \\
\text { tip of the guidewire }\end{array}$ & Not hazardous \\
\hline $\begin{array}{l}\text { [CA8] Insert the } \\
\text { catheter over the } \\
\text { guidewire }\end{array}$ & Not hazardous & $\begin{array}{l}\text { [UCA13] Insert catheter } \\
\text { over guidewire provided } \\
\text { when guidewire does not } \\
\text { remain in place, i.e. } \\
\text { moves deeper inside vein }\end{array}$ & $\begin{array}{l}\text { [UCA14] Insert the catheter over } \\
\text { the guidewire provided wrongly, } \\
\text { before the anaesthetist pinches the } \\
\text { external tip of the guidewire }\end{array}$ & $\begin{array}{l}\text { [UCA15] Insert the catheter over } \\
\text { the guidewire stopped too soon } \\
\text { when the external tip of the } \\
\text { guidewire is not reachable }\end{array}$ \\
\hline $\begin{array}{l}\text { [CA9] Remove the } \\
\text { guidewire }\end{array}$ & $\begin{array}{l}\text { [UCA16] Remove the } \\
\text { guidewire not provided when } \\
\text { catheter placement is } \\
\text { completed }\end{array}$ & Not hazardous & $\begin{array}{l}\text { [UCA17] Remove the guidewire } \\
\text { provided too late, i.e. } \\
\text { postoperative, when the patient } \\
\text { has already undergone the surgery }\end{array}$ & Not hazardous \\
\hline \multirow{2}{*}{$\begin{array}{l}\text { [CA10] Place the } \\
\text { guidewire in the tray }\end{array}$} & \multirow{2}{*}{$\begin{array}{l}\text { [UCA18] Place the guidewire } \\
\text { in the tray not provided when } \\
\text { CVC process is completed; i.e. } \\
\text { no way to check whether the } \\
\text { guidewire was removed from } \\
\text { patient or not }\end{array}$} & \multirow{2}{*}{ Not hazardous } & $\begin{array}{l}\text { [UCA19] Place the guidewire in the } \\
\text { tray provided too late when } \\
\text { surgeon takes over }\end{array}$ & \multirow{2}{*}{ Not hazardous } \\
\hline & & & $\begin{array}{l}\text { [UCA20] Place the guidewire in tray } \\
\text { provided too late i.e., when patient } \\
\text { has undergone surgery }\end{array}$ & \\
\hline $\begin{array}{l}\text { [CA11] Secure the } \\
\text { catheter in the skin }\end{array}$ & N/A for the specific hazard & Not hazardous & $\begin{array}{l}\text { [UCA21] Secure catheter in skin } \\
\text { provided too early before checking } \\
\text { whether guidewire is removed }\end{array}$ & Not hazardous \\
\hline
\end{tabular}

